シフェニルベンチシン試薬によるかん詰 原料中の硝酸塩の簡易検定法について 岩本喜伴* - 宮崎正則* ・国里進三* ・前田琩子*

Approximate determination of nitrate in Agricultural Products with Diphenylbenzidine Reagent

Yoshitomo Imamoto, Masanori Miyazaki, Shinzo Kunisato, and Yuuko MaEda

A spot test method with diphenylbenzidine for rapid and approximate estimation of nitrate was examined. On tomato juice, $1 \mathrm{ppm}$. of nitrate- $\mathrm{N}$ was found to be detectable by this method, and the obtained values were in good agreement to those by the $m$-xylenol method of A.O.A.C. and the cadmium-column method proposed by Камм.

(Received November 30, 1967)

近年，果计，野菜類などのかん詰でその原料中に含ま れている硝酸塩によるスズの異常溶出による事故が散発 的に発生した。

かん詰使用水中の硝酸塩含量は，G.R. 硝酸試薬など》 で簡単に $1 \mathrm{ppm}$ 以下をで測定できるが，天然物中に含 まれている硝酸塩の定量法としては, 現在 $m$-xylenol 法"，Cdカラム法8がー般的使用されているが，これら の方法注測定に時間を要し煩雑である。植物の窒素栄養 診断の簡易検定法として diphenylamine 法 (以下 DPA 法と略す), phenyl disulphonic acid 法, Bray's 法") などがあり，N.C.A. (米国かん詰協会)では DPA 法を 採用しトマト果実中の硝酸塩の簡易測定に使 用してい る。しかしこれらの方法はいずれも $5 \mathrm{ppm}$ 以下の硝 酸性空素の測定には使用できず，DPA 法の検出限度は $6 \mathrm{ppm}$ 程度であった。

著者らは，かん詰原料となる農産物および充てん前の 内容物中に含まれている硝酸塩量をチェックし，かん詰 となった場合のスズの異常溶出による事故を末然に防止 するため, diphenylbenzidine (以下 DPB と略す) 試 薬们による硝酸塩简易測定法を採用した。この DPB 法 とDPA 法を比較俟討した結果, DPB 法はDPA 法より む6 7 倍鋭敏で，硝酸性空素標準溶液こは $1 \mathrm{ppm}$ 以下 まで検出でき，測定操作も非常に簢便で圌場やかん詰工 場内でむ現場向の測定法として適用できることが明らか となったので，つきに測定方法を報告する。
1. 分析方法

(1) 試薬

i) DPB 試薬：DPB $0.05 \mathrm{~g}$ を空素分析用浱硫酸 50 $\mathrm{m} l$ に溶解し，かっ色の滴びんに貯える。試薬溶液の色 が浱くなれは，比色の判定に誤差を生ずるから新しく調 製する。

ii）標準硝酸性窒素原夜：純硝酸カリウム $\left(\mathrm{KNO}_{8}\right)$

$0.7218 \mathrm{~g}$ を上って蒸留水または脱イオン水に溶かし, 全 量を $1,000 \mathrm{ml}$ 定容とする。本溶液は硝酸性窒素 100 ppm の原液となる。

iii）比色標準溶液：標準硝酸性窒素原液定 0.5，1.0， $3.0,6.0,10.0 \mathrm{~m} l$ を各々 $100 \mathrm{~m} l$ 容のメスフラスコに 入れる。蒸留水また脱イオン水で $100 \mathrm{~m} l$ 定容とする。 これらの溶液は硝酸性谼素 $0.5,1.0,3.0,6.0,10.0$ ppm となる。本溶液は毎週調憋して使用する。

iv）窒素分析用浱硫酸：試薬特級品の硫酸中にも微量 の硝酸塩が合まれているため，硫酸を蒸発皿に入れ，砂 浴上で硫酸の白社が発生するまで加熱し硝酸塩を除去し た硫酸を使用する。

(2) 器具

i) スポットプレート

ii）小型ペンチ

(3) 検定方法

比色標準溶液をスポットプレート上に 1 滴ずつ滴加す る。別に検体を小型ペンチをたは手で圧㩁して，液汁を 1 滴スボットプレート上にとる。スボットプレートを動 かし検液を橮拌しながら DPB 試薬を5〜6 滴滴加する。 （呈色は硫酸濃度に関俰するので，試薬溶液をかずか過 剩に滴加する。）硝酸塩が存在すれば青らん色を呈する。 このときの色調を比色標準溶液の色調と比較して検液中 の硝酸塩濃度を判定する。(この反応は非常侸鋭敏であ るが短時間内に退色するので 2 5 分以内に色調を判定 する。)

\section{2. 検定結果および考察}

DPB 法と N.C.A. で採用されている DPA 法による 呈色の比較を比色標準浴液について行なった結果, DPB 法では $0.5 \mathrm{ppm}$ から $10 \mathrm{ppm}$ の硝酸性窒素をで判定で きるが，10 ppm 以上になると呈色が浱くなって差異の 判定はつけがたい。DPA 法では硝酸性窒素 $6 \mathrm{ppm}$ 程度 が検出限界であった。実際試料としてトマトジェースの 遠沈上清（硝酸塩を検出しないもの）に硝酸性窒素とし $\tau 0,0.5,1.0,3.0,6.0,10.0 \mathrm{ppm}$ になるように硝

* 財団法人東洋食品研究所（兵庫県川西市寺畑）

Toyo Institute of Food Technology. Kawanishi, Hyogo. 
酸カリウムを添加した溶液を調製し， DPB 法と DPA 法による呈色の比較を行なった。天然物について実施し た場合には，試薬溶液が涱硫酸であるため褐色化現象が 認められるが， DPB 法では $1 \mathrm{ppm}$ 程度まで判定でき る。しかし，DPA 法では $6 \mathrm{ppm}$ 以上の硝酸性窒素で ないと判定できない。すなわち，DPB 法は DPA 法よ りも 6〜7 倍鋭敏であることが判明した。

検液の糖濃度が高い場合とか，パルブ質が多い場合に は褐色化現象を起こしやすく，また一度に多量の試薬溶 液を滴加したときにもこのような現象が現われるが，掜 洋しながら試薬溶液を滴加すると比較的良好な結果がえ られた。この褐色化現象防止についてはさらに検討を加 えたい。

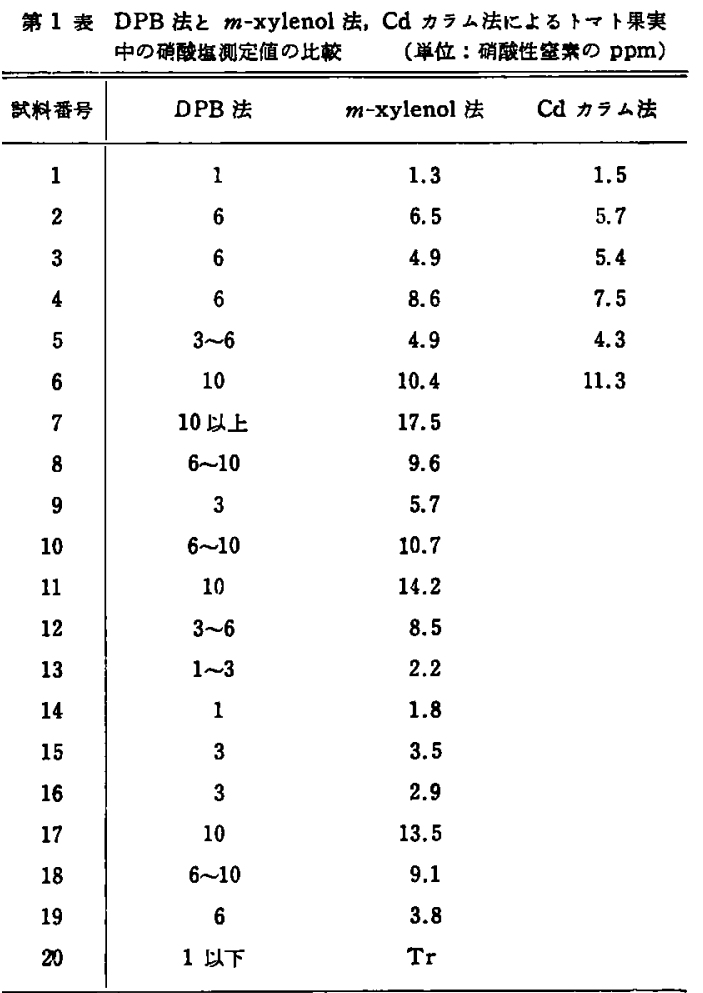

トマト果実について DPB 試薬による簡易検定結果と $m$-xylenol 法, Cd カラム法による測定結果の比較を行 なった。この結果を第 1 表に示した。この結果から，褐 色化現象が認められるにもかかわらず DPB 法は硝酸性 窒素 1 10 ppm 程度の範囲内で $m$-xylenol 法, $\mathrm{Cd}$ カ ラム法と比較し近似的な值がえられた。

\section{3. 要約}

本報で提唱した DPB 法をDPA 法ならびに $m$-xylenol 法, Cd カラム法と比較検討した結果，次の事柄が明ら かとなった。

(1) DPB 法は DPA 法よりも6 7 倍鋭敏であって， 硝酸性空素標準溶液では $0.5 \mathrm{ppm}$ から $10 \mathrm{ppm}$ まで判 定できるが, $10 \mathrm{ppm}$ 以上になると呈色が涱くなるので 差異の判定はつけがたい。またトマトジニースでは，有 機物の存在のため褐色化現象が認められるにるかかわら ず, 1 ppm まで判定できる。

（2）トマト果実饥つて，DPB 法による判定值と $m$ xylenol 法や Cd カラム法で測定した值は，注同じ結 果がえられた。

(3) DPB 法は操作が非常に簡便であって，國場やか ん詰工場内でかん詰原料中の硝酸塩簡易検定のための現 場向の測定法として十分使用できる。

おわりに，本研究を行なうにあたり終始有益な御教示 を賜わった，東洋製镆株式会社技術本部・研究部に哚く 感謝いたします。

$$
\text { 文献 }
$$

1) 東京大学農学部農芸化学教室: 実駼農芸化学, 別 巻, (朝合書店), p. 76 (1964).

2) Method of Analysis of A.O.A.C., 9 th. ed., 23.013 p. 298 (1960).

3) Камм, L., McKeown, G.G. and Sмith, D.M.: J. Assoc. Offic. Anal. Chemists, 48, 892 (1965).

4) 杉山直俄・高橋和彦：園芸，27，161 (1958).

5) Frigl, F.: Spot Tests in Organic Analysis, 6 th. ed., (Elsevier), p. 178 (1960).

(1967 年 11 月 30 日受理) 